\title{
Toward Written Error Correction with a Japanese-English Parallel Corpus: Data-Driven Learning in the Japanese EFL Classroom
}

\author{
Michael McGuire \\ Kansai Gaidai University \\ doi: https://doi.org/10.7820/vli.v08.1.McGuire
}

\begin{abstract}
The concept of data-driven learning (DDL) - direct student use of corpora - has been gaining attention among researchers and teachers. DDL gives learners the chance to take an inductive approach to learning by recognizing patterns in corpus data rather than following abstract rules. However, very few studies focus on presenting clear practices that other teachers can readily use in their classes, particularly related to written error correction. This paper begins by reviewing research pertaining to DDL in student writing as well as using Japanese-English parallel corpora. It then outlines a recent study by Jenifer Larson-Hall (2015), notes weaknesses in the study, and outlines a current project (McGuire \& Larson-Hall, under preparation).
\end{abstract}

Key words: Data-driven learning; written error correction; parallel corpora; corpus linguistics.

\section{Introduction and Background}

Linguists and language educators have been using corpora for many years to gain deeper insights into the usage of language and to create more authentic learning materials. The ability to measure word and collocation frequency in massive collections of authentic text has led to more objective perceptions of language in use and the ability to reevaluate language instruction.

The concept of data-driven learning (DDL) - direct student use of corpora has been gaining attention among researchers and teachers. DDL posits "that the language-learner is also, essentially, a research worker whose learning needs to be driven by access to linguistic data" (Johns, 1991, p. 2). The corpus becomes an environment for the learner to explore independently through their own inquisitiveness. A corpus provides students with extensive context, which can be used for discovery-based learning. Rather than just looking up the meaning of a word in a dictionary, students can use a corpus to see how common a word is, how it is used in sentences, what words frequently appear alongside it, whether it is used more often in spoken or written language, and a wealth of other useful information that cannot be provided by a rule-based learning approach. DDL gives learners the chance to take an inductive approach to learning by recognizing patterns in language rather than following abstract rules that have been handed to them. 
One of the central elements of DDL that students will engage with is the Key Words in Context (KWIC) display format. This formatting aligns numerous in-line occurrences of a key word down the center of the page with sentence context on either side. This allows users to easily see the words that come immediately before and after the key word in many examples on the same page. Figure 1 shows KWIC results for the word budge from the Corpus of Contemporary American English (COCA). This particular search is focusing on the words that come before the key word, and it quickly reveals that the word to appears multiple times immediately before budge. Looking further to the left shows different forms of refuse, suggesting that refuse to budge is a recurrent collocation. DDL methods require students to find patterns in language on their own, and the KWIC format is particularly helpful at making such patterns more visible. This requires students to spend time analyzing search results and looking at example sentences, but that process is one of the focuses of DDL. "DDL may help learner development if it leads, for example, to increased language sensitivity, noticing, induction, and ability to work with authentic data" (Boulton \& Cobb, 2017, p. 2).

One useful feature of KWIC format is that it works well as a printout for paper-based DDL. Several studies have shown that tasks involving teacher-prepared KWIC printouts help acquaint students with analyzing corpus search results (Allan, 2006; Boulton, 2008b, 2009b; Chambers, 2007; Tian, 2005). A few paper-based DDL activities could help prepare students for the real thing. In fact, strictly paper-based DDL activities have been shown to be just as effective as computer-based DDL or a combination of the two in TOEIC vocabulary acquisition (Chujo, Anthony, Oghigian, \& Uchibori, 2012), so teachers who do not have access to computers in the classroom or do not wish to use them constantly can still employ DDL. However, there are some crucial differences between paper-based DDL and computer-based DDL. First, the preparation of paper-based DDL activities has been known to take a great deal of time (Boulton, 2008b; Johns, 1991), which may prevent many teachers from adopting it in their classes. Searching for, analyzing, and selecting appropriate KWIC concordance

\begin{tabular}{|c|c|c|}
\hline a cry, skinny legs flailing. The other refused to & budge & eventually sliding down the bank on his stomach only after his \\
\hline through the rows of plants. Disgusted , Sadie refused to & budge & another inch. \# "Come on. You are n't scared \\
\hline blister up there. \# Lawson's boyhood self refused to & budge & . \# Awright then . His father tossed the bucket toward the \\
\hline What actually happened was that the golden thing refused to & budge & from its hiding place. Reasoning that it must he far heavier \\
\hline of kin from about 300 Ocean City residents who refused to & budge & . They would be on their own, they were told. \\
\hline out, the team lost only Schulters, who refused to & budge & from his $\$ 5$ million signing-bonus demand. The longer the \\
\hline you ." The stalk beginswhen a bull refuses to & budge & Schearer sneaks to within 300 yards of the bull and his \\
\hline to sneak out of the fare. The driver & budge & . The ensuing stalemate causes another 43 to stack up behind. \\
\hline percent is far too much. The players union refuses to & budge & from that position, and the owners have -- have drawn a \\
\hline power-hungry executive, a czar , a person who & budge & from his enigmatid decisions and someone who has drastically \\
\hline There may still be a stalemate, both sides refusing to & budge & But for the workers it is a losing battle, because \\
\hline I am in bed sleeping like a teenager refusing to & budge & Dad is down the hall in his room. Stretching. \\
\hline an issue on which the party just ca n't seem to & budge & , and that is the issue of choice. And I want \\
\hline hammer to knock us loose when we are too set to & budge & ( Jeremiah ) ? Is it food sweeter than honey for those \\
\hline but once it 's in place, it 's tough to & budge & I found the Psyclone to have the best staying power of \\
\hline who-knew-what in an abandoned receptacle? \# Holly tried to & budge & the box. It shimmied but held fast. She rocked it \\
\hline
\end{tabular}

Figure 1. KWIC results for the word "budge" from the Corpus of Contemporary American English. 
lines that clearly illustrate a specific pattern is no easy task. Instead, giving students the opportunity to freely examine the data themselves can be beneficial. Paper-based DDL deprives the learner of the explorative component of direct corpus use. Many times finding patterns requires multiple searches (Gaskell \& Cobb, 2004), requiring students to test and refine search terms on their own. Through this practice, students can better build the metalinguistic awareness needed for effective DDL (Yang, Wong, \& Yeh, 2013).

Both computer-based and paper-based DDL have been shown to be effective and efficient by two empirical meta-studies. These two meta-analyses used Cohen's $d$ to measure effect size as the difference between either control and experimental groups or pre/posttest scores from the collected studies. Then, a mean Cohen's $d$ was calculated for all of the studies combined. Boulton and Cobb's extensive 2017 meta-analysis looked at 88 effect sizes from different DDL studies from 1989 to 2014 and found significant overall effects $(d=0.95$ for control/experimental studies and $d=1.50$ for pre/posttest studies). Mizumoto and Chujo's meta-analysis of 32 effect sizes from DDL studies in Japanese EFL classrooms (2015) also returned positive results $(d=0.99)$. Both of these meta-studies indicated that DDL shows the greatest effects in learning lexicogrammar, or "how the target word fits into its surroundings" (Boulton \& Cobb, 2017, p. 33), usually through collocation and colligation.

Data-driven learning can be applied in many different ways, but the majority of studies deal with inductive noticing from either paper-based or computer-based KWIC results. While most studies do not concentrate on practical classroom application, Chujo and Oghigian (2008, p. 5) lay out a series of clear DDL exercises which illustrate how students can use a corpus to learn lexicogrammar. In their study, students explored the KWIC results of several instructor-provided search terms in order to create hypotheses on particular patterns or rules. One such search term was the single word quality. Students were asked to note the words that appear before and after it in order to induct basic noun phrase structure. The search reveals a common pattern: an article before quality and a prepositional phrase after, as in the quality of education. Other searches included: enjoyed to find what often follows (gerunds rather than infinitives), discuss to find wh-clauses (discuss when), furniture* and passenger* to distinguish countable and uncountable nouns, and several more. Once students had been given time to explore and come up with their own hypotheses, they were given explicit explanations of the rules in order to verify their ideas. After this, students were given follow-up worksheets where they needed to apply the rules in language production. In this manner, Chujo and Oghigian applied a combination of inductive and deductive approaches which proved effective.

Other studies have examined an inductive approach to many different language features. Smart's (2012) students used corpus data to study a variety of grammar features: subject-verb agreement, phrasal verbs, active and passive voice, relative clauses, and finite compliment clauses. Other studies have looked at learning collocations (Alshaar \& AbuSeileek, 2013; Ashouri, Arjmandi, \& Rahimi, 2014; Chan \& Liou, 2005; Chen, 2011; Sun \& Wang, 2003), phrasal verbs (Boulton, 2008b), linking adverbials (Boulton, 2009b; Cotos, 2010, 2014), and prepositions (Hadi \& Alibakhshi, 2012; Someya, 2000). Gaskell \& Cobb (2004) found that providing teacher-selected KWIC examples as feedback for particular kinds of written errors helped students to correct them in revisions. 
Johns (1991) initially imagined DDL as a tool for advanced learners, but a number of studies have shown it to be beneficial to lower level learners as well (Boulton, 2008a, 2009b; Chujo, Anthony, Oghigian, \& Yokota, 2013; Chujo \& Oghigian, 2012; Cobb, 1997, 1999a, 1999b). There is some debate as to how much training, if any, is necessary before students can make use of concordance data. Some studies assert that extensive training is essential before using a corpus (Breyer, 2006; Gaskell \& Cobb, 2004; Turnbull \& Burston, 1998; Yang et al., 2013), while others have found evidence that students can benefit from DDL with little training (Boulton \& Wilhelm, 2006) or with no training at all (Boulton, 2009b). The key challenges that are revealed from the discussion of training are (a) if students can switch from a deductive to inductive approach and (b) if students can make sophisticated use of a corpus autonomously. The hope is that with enough hands-on practice, students can do both, so emphasis could be placed on independent practice with feedback rather than guided training.

Despite all of this research on DDL, very few studies focus on presenting clear practices that other teachers can readily use in their classes. The majority of the studies mentioned above used offline corpora with concordance software and the article discussions concentrated on the results of pre/posttests rather than the instruction and activities involved. So, while the results of studies are often encouraging, the procedures cannot be easily replicated by other teachers. It is clear that for DDL to be more widely accepted as a viable methodology, it needs to move from theory to more accessible practice.

\subsection{Data-Driven Learning with Parallel Corpora}

Data-driven learning is a promising approach to language learning, but it is easy to see some of the challenges that might be encountered. Learning is based on student autonomy and motivation. Students are put "at the center of the process, taking increased responsibility for their own learning rather than being taught rules in a more passive mode" (Boulton, 2009a, p. 82). Under DDL, the roles of both the teacher and student shift, which can be problematic. Students must take a more active role, and teachers must step back from controlling the learning process. On the technical side, students have reported that they find concordance software difficult to use (Farr, 2008) and the monolingual concordance results difficult to understand (Aston, 2001; Tian \& Liu, 2004).

A parallel corpus (a bilingual corpus built from translations between two languages that displays both simultaneously) may help to alleviate some of the challenges of using DDL in the EFL classroom. When a student searches a parallel corpus, the results are given in both languages, giving students the opportunity to analyze word usage in English and compare it to their native language. A number of studies have looked at using Japanese-English parallel corpora in the Japanese EFL classroom. Students responded positively and found a parallel corpus useful (Chujo, Utiyama, \& Miura, 2006), and students in a DDL treatment group made greater improvements in learning TOEIC vocabulary and grammar than a non-DDL control group (Chujo, Anthony, \& Oghigian, 2009). 
While these studies are promising, challenges remain. McGuire (2018) argues that students who are not familiar with a parallel corpus may initially treat it like a bilingual dictionary. They use it to look for a quick one-to-one word replacement rather than looking at the usage and context. Many students expect a quick "answer" from their electronic dictionaries (and more recently machine translation websites and apps) and thus may treat a corpus in much the same way. Some students simply use the first result they see, which can create bizarre word-choice problems. Another impediment is that strict grammar-translation teaching is still prevalent in Japan, even at universities. Many students are required to remember exact sentence translations and reproduce them accurately. This trains them to treat language translation as mechanical and prevents them from "developing the mind-set for the deeper syntactic analysis of language needed to use a parallel corpus effectively" (McGuire, 2018, p. 257).

There has up to now been a paucity of research regarding the use of a parallel corpus for error correction in student writing. Chujo, Utiyama and Miura's 2006 study asked participants at one point to attempt to translate Japanese phrases into English using a parallel corpus. This study was only looking at student reactions to using the corpus in this manner and did not try to quantifiably measure if students could successfully make the translations. Yang, Wong, and Yeh (2013) had participants look at a Chinese sentence and then rearrange scrambled English words into the "correct" translation as taken from a Chinese-English parallel corpus. This did not involve any original writing on the part of the students, and the focus of the study was on developing students' metalinguistic awareness rather than correcting written errors.

In her 2015 study, Larson-Hall asked if Japanese university EFL students could identify and correct written mistakes by using a Japanese-English parallel corpus. In this study, the parallel corpus was treated as a reference for students to use in place of a bilingual dictionary. As a pretest, students in academic writing classes were asked to correct a flawed English translation of a Japanese paragraph written by an anonymous Japanese student. The translation contained many grammatical and lexical mistakes, and the students were asked to correct any problems they found. None of the mistakes were marked or identified, but the students were allowed to use dictionaries or other resources. Following this, the DDL focus group was given two 90-min training sessions to use the parallel corpus to correct written mistakes. This training involved making corrections to teacher-led worksheets of erroneous English translations of Japanese sentences. The control group was given no training or in-class access to the parallel corpus. Over 12 weeks, both groups continued their regular studies in their academic writing classes. The DDL focus group was encouraged to use the parallel corpus over the course of the semester to help with their writing. At the end of the 12 weeks, all students were given a posttest identical to the pretest. They were again asked to correct any mistakes that they found, and all students were allowed to see what they wrote on their pretests. Pretests and posttests were analyzed to see if the students were able to improve in error identification and correction over the course of the 12 weeks. The results were mixed and inconclusive. Some students in the treatment group were able to improve, while others were not. 
While the questions asked in Larson-Hall's 2015 research are very important, a few issues call for a new revised study:

First, error identification was left to the students and played a very central part. It seems obvious that foreign language students have difficulty identifying mistakes in their target language, especially in their own writing. Many of the students in both the focus and control groups made corrections where none were needed or made corrections in the wrong place. Students reported that they could sense that something was wrong with a sentence, but they could not specifically identify the error. A new study should not make error identification such a key component, but rather test if students can sufficiently correct instructor-identified errors.

Additionally, in order to have a standardized pre/posttest, students were required to correct the translation mistakes of another student. The idea was that the students would be able to read and understand the author's original ideas in Japanese and then find mistakes in the English translation. However, several students who participated in the study reported that they didn't know what the author wanted to say. Since the writing was not their own, it is understandable that they felt removed from the ideas. This issue makes using a standardized pre/posttest difficult. A new study would need to look directly at the mistakes in each participant's compositions over the course of the study period. By doing so, changes in error rate and improvements in error correction can be measured for each student.

Finally, the DDL focus group classes were not conducted in a computer lab after the corpus training was complete. Because of this, students could not use the parallel corpus while they were writing in class or receive direct feedback on their search skills. Students were asked to mark areas in their compositions where they consulted the corpus, but there was no way to judge how much time each student actually spent doing hands-on DDL. The DDL focus group in a new study should have constant access to the parallel corpus and be encouraged to use it in all stages of composition.

\subsection{Planned Methodology}

To address the above-mentioned issues with Larson-Hall (2015), a new study will need to be conducted.

To fix the problem of student error identification, an indirect error tagging system will be introduced. Rather than the common practice of explicitly correcting mistakes with a red pen, instructors in the study will use highlighters to mark the words involved in an error. Different colored highlighters will be used to differentiate grammatical mistakes from problems with word choice. Once the instructor has tagged mistakes, the students will then be given time to use the parallel corpus to try to correct them. After attempting correction, the instructor can judge if the student has adequately fixed the mistake or if more work is needed. This process could be repeated on multiple drafts as necessary.

This system could easily be used by any teacher and will not be as timeconsuming as explicit correction. Additionally, this error tagging system will give students more focused and personal practice using the parallel corpus, which 
should then lead to more effective utilization of it. As students improve at using the parallel corpus, they will likely use it more effectively for their subsequent writing assignments as well. The new study will measure whether or not this system leads to improved error correction and ultimately to a decrease in the number of mistakes made in student writing submissions.

\subsection{Eijiro on the WEB Parallel Corpus}

The parallel corpus utilized in Larson-Hall's 2015 study deserves more attention, as it does not seem to appear in any other studies thus far. The parallel corpus is publishing company ALC's online implementation of the Eijiro (英辞郎) corpus, from here on referred to as Eijiro on the WEB. It is developed and constantly updated by the Electronic Dictionary Project (EDP) and currently contains over 2 million lemma entries from over 700,000 bilingual newspaper texts. The PRO version which will be discussed here contains over 1 million aligned parallel sentences. It is one of the most accessible Japanese-English parallel corpora for the following reasons:

First, Eijiro on the WEB is accessible online and does not require additional concordance software. It can be accessed by computer or smartphone, making it usable in a regular classroom without a computer for each student. As long as students have smartphones they can access the corpus.

Second, it is a general purpose corpus compiled from translated newspaper articles and is not overly technical or field specific. Other larger English-Japanese parallel corpora exist, but they have a limited range of sources such as the Asian Scientific Paper Excerpt Corpus (ASPEC) which is comprised of parallel scientific abstracts, the Japanese-English Subtitle Corpus (JESC) which is a collection of parallel film subtitles, or the Kyoto Free Translation Task (KFTT) created from parallel Wikipedia articles about Kyoto. Chujo et al. $(2006,2009,2012)$ used the Japanese-English News Article Alignment Data (Utiyama \& Isahara, 2003), which is larger than the Eijiro corpus. However, all of these corpora are just raw data without any web interface or search engine and require separate concordance software to use. Because the accessible web interface is easy for students to use, McGuire and Larson-Hall have always chosen to work with the Eijiro corpus.

Third, Eijiro on the WEB's search engine is familiar, straightforward, and easy to use. It is a simple search bar; and users can search in English, Japanese, or even both at the same time without adjusting settings. Granted, it is not as powerful as a full feature corpus interface like Mark Davies Corpus of Contemporary American English (2008-), but it is much more approachable for people who are unfamiliar with corpus linguistics. ALC's search engine offers some more advanced syntax search abilities and includes bilingual KWIC search results (see Figure 2) and collocation frequency charts (see Figure 3).

Finally, it is not particularly expensive to use. The PRO version costs 324 yen per month or 3564 yen for a yearly subscription. However, the first month is free, which makes it viable for short-term use with large numbers of students. The basic version that only contains word and phrase translations is always free to use, but it does not include all of the sentence data. The basic version is more of a bilingual phrase dictionary than a corpus, but it can also be useful for students. 


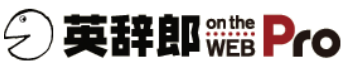

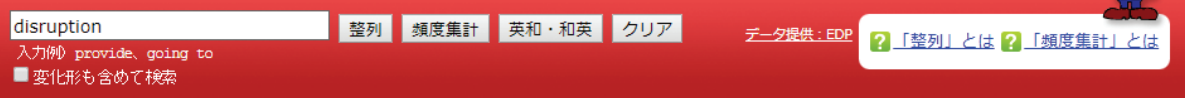

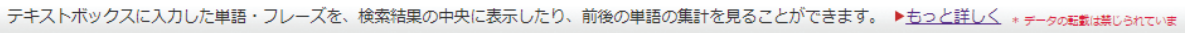
説明を見る

| 検索文字列 disruption（絞り込み検索条件 - 追加する : なし

該当件数：223件

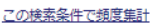

\begin{tabular}{l|l|l|l|l|l|l|l}
\hline & 2 & 3 & 4 & 5 & 次入
\end{tabular}

左2語目 左1語目

右1語目 右2語目

disruption $n$ might cause in someone's life

詳细+

verty, conflict, infectious diseases and environmental $d$ sr $^{2}$ That led to disruption among the Imperial nobles, by which they became factio ....詳細 specially Hirobumi ITO as a person who led to national disruption, and also there were some members who were dissatisfie ....詳細 + ure and other parts of western Japan on Friday brought disruption and anxiety to many people in the region.

classroom disruption and chaos

as a result, it caused a distribution classroom disruption and lack of order

- The exam was conducted without further disruption, and the university will not adjust the test scores, it said.

試験は混乱なく行われ、採点への配虐はしないという。・绌典】日英新閆記事対応付けデー夕(国立研究開発法人情報通信研究機構)

ses, such as those due to speed restriction or traffic disruption and to various kinds of damage, including damage to he anced, but on the other hand, the phenomenon of "class disruption" became evident in schools, and juvenile crime and chi ter finds it necessary for avoiding the risk of severe disruption being caused in the financial system in Japan, he/she re aware because they have firsthand experience of the disruption brought to their lives by the need to accommodate view the necessary protection against the threat of violent disruption by counter-demonstrators.

to preach a 'juvenile mind' theory (pure mind prior to disruption by existing morals), and eventually even denied Koshi tidal disruption by Jupiter's gravity

$\ldots 1$ be able to enjoy these major sporting events without disruption by serious incidents or calamities.

Figure 2. KWIC search results for "disruption" in ALC's Eijiro on the WEB PRO. Entries are expandable to show Japanese translation and source.

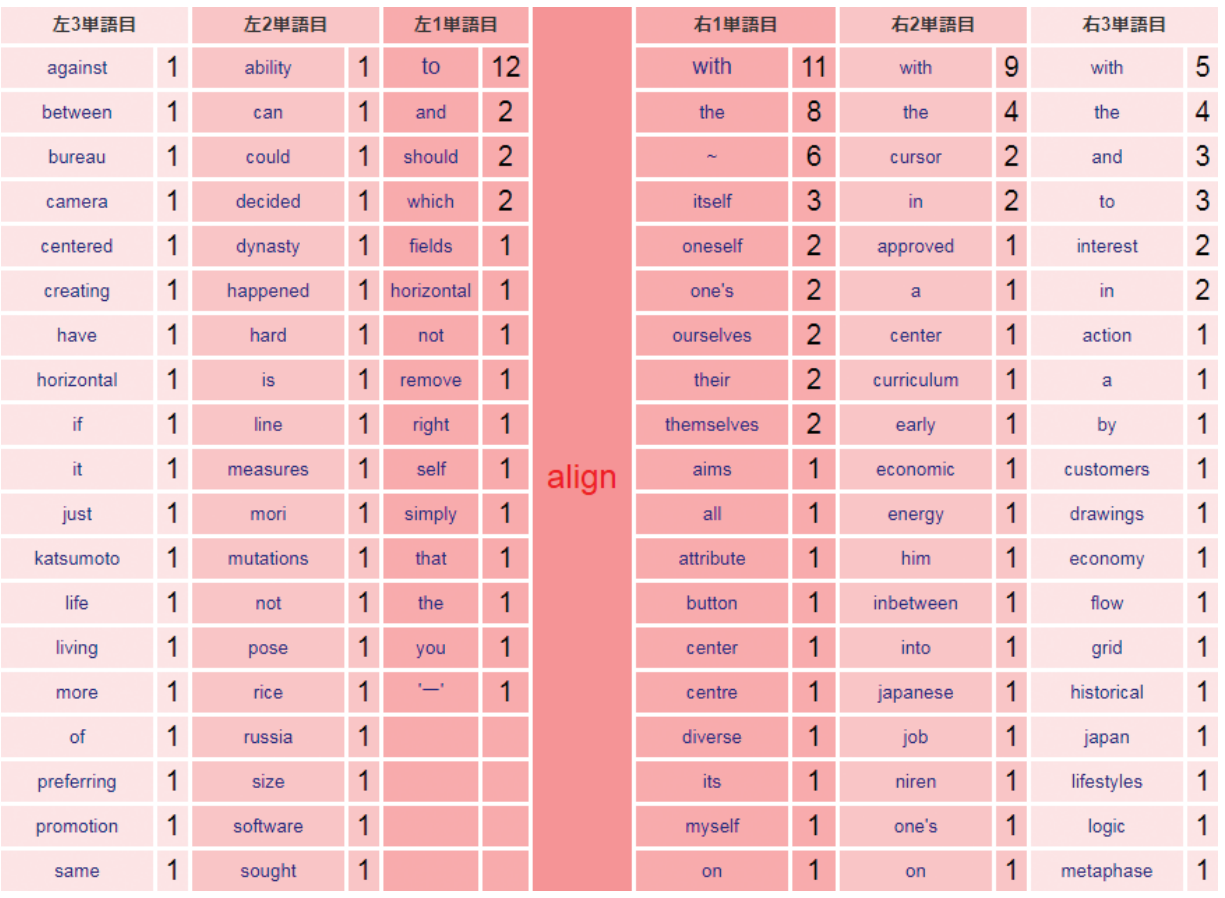

Figure 3. Collocation frequency chart for "align" in Eijiro on the WEB PRO. 
The combination of a parallel corpus and bilingual dictionary on the same site makes it more versatile.

Ultimately, wider adoption of DDL practices will require more accessible tools, and more studies will be needed to empirically show the benefits of such tools. As mentioned before, most DDL studies up until now use raw corpus data in concordance software, which greatly restricts where and when students can engage with the data. Eijiro on the $W E B$ is a viable option for EFL teachers in Japan who want to bring DDL to their classrooms and for students who want to directly explore concordance data.

\section{References}

Allan, R. (2006). Data-driven learning and vocabulary: Investigating the use of concordances with advanced learners of English. Centre for Language Communication Studies, Occasional Paper, 66, 1-52.

Alshaar, A. A., \& AbuSeileek, A. F. (2013). Using concordancing and word processing to improve EFL graduate students' written English. JALT CALL Journal, 9(1), 59-77.

Ashouri, S., Arjmandi, M., \& Rahimi, R. (2014). The impact of corpus-Based Collocation Instruction on Iranian EFL Learners' Collocation Learning. Universal Journal of Educational Research, 2(6), 470-479.

Aston, G. (2001). Learning with corpora. Houston, TX: Athelstan.

Boulton, A. (2008a). DDL: Reaching the parts other teaching can't reach? Paper presented at the Teaching and Language Corpora 8, Lisbon, Portugal.

Boulton, A. (2008b). Looking (for) empirical evidence of data-driven learning at lower levels. In L.-T. Barbara (Ed.), Corpus Linguistics, Computer Tools, and Applications: State of the Art (pp. 581-598). Frankfurt: Peter Lang. Lodz Studies in Language.

Boulton, A. (2009a). Data-driven learning: Reasonable fears and rational reassurance. Indian Journal of Applied Linguistics, 35(1), 81-106.

Boulton, A. (2009b). Testing the limits of data-driven learning: Language proficiency and training. ReCALL, 21(1), 37-54. doi:10.1017/S0958344009000068.

Boulton, A., \& Cobb, T. (2017). Corpus use in language learning: A meta-analysis. Language Learning, 67(2), 348-393. doi:10.1111/lang.12224.

Boulton, A., \& Wilhelm, S. (2006). Habeant Corpus - they should have the body. Tools learners have the right to use. ASp, 49-50, 155-170. doi:10.4000/ asp.661.

Breyer, Y. (2006). My Concordancer: Tailor-made software for language learners and teachers. In S. Braun, K. Kohn, \& J. Mukherjee (Eds.), Corpus Technology and Language Pedagogy (pp. 157-176). Frankfurt am Main, Berlin, Bern, Bruxelles, New York, Oxford, Wien: Peter Lang.

Chambers, A. (2007). Popularising corpus consultation by language learners and teachers. In E. Hidalgo, L. Quereda, \& J. Santana (Eds.), Corpora in the 
Foreign Language Classroom Language and Computers (Vol. 61, pp. 1-16): UNSPECIFIED, Brill. doi:10.1163/9789401203906_002.

Chan, T. -P., \& Liou, H. -C. (2005). Effects of web-based concordancing instruction on EFL students' learning of verb-Noun collocations. Computer Assisted Language Learning, 18(3), 231-251. doi:10.1080/09588220500185769.

Chen, H. -J. H. (2011). Developing and evaluating a web-based collocation retrieval tool for EFL students and teachers. Computer Assisted Language Learning, 24(1), 59-76. doi:10.1080/09588221.2010.526945.

Chujo, K., Anthony, L., \& Oghigian, K. (2009). DDL for the EFL classroom: Effective uses of a Japanese-English parallel corpus and the development of a learner-friendly, online parallel concordancer. Paper presented at the 5th Corpus Linguistics Conference, University of Liverpool, UK.

Chujo, K., Anthony, L., Oghigian, K., \& Uchibori, A. (2012). Paper-Based, computer-Based, and combined data-Driven learning using a web-Based concordancer. Language Education in Asia, 3(2), 132-145. doi:10.5746/LEiA/12/ V3/I2/A02/Chujo_Anthony_Oghigian_Uchibori.

Chujo, K., Anthony, L., Oghigian, K., \& Yokota, K. (2013). Teaching remedial grammar through data-driven learning using AntPConc. Taiwan International ESP Journal, 5(2), 65-90.

Chujo, K., \& Oghigian, K. (2008). A DDL approach to learning noun and verb phrases in the beginner level EFL classroom. Paper presented at the 8th International Conference on Teaching and Language Corpora, Lisbon, Portugal.

Chujo, K., \& Oghigian, K. (2012). DDL for EFL beginners: A report on student gains and views on paper-based concordancing and the role of L1. In J. Thomas \& A. Boulton (Eds.), Input, Process and Product: Developments in Teaching and Language Corpora (pp. 170-183). France, Brno, Czech Republic: Masaryk University Press.

Chujo, K., Utiyama, M., \& Miura, S. (2006). Using a Japanese-English parallel corpus for teaching English vocabulary to beginning-level students. English Corpus Studies, 13, 153-172.

Cobb, T. (1997). Is there any measurable learning from hands-on concordancing? System, 25(3), 301-315. doi:10.1016/S0346-251X(97)00024-9.

Cobb, T. (1999a). Applying constructivism: A test for the learner-as-scientist. Educational Technology Research Development, 47(3), 15-31. doi:10.1007/ bf02299631.

Cobb, T. (1999b). Breadth and depth of lexical acquisition with hands-on concordancing. Computer Assisted Language Learning, 12(4), 345-360. doi:10.1076/ call.12.4.345.5699.

Cotos, E. (2010). Automated writing evaluation for non-native speaker English academic writing: The case of IADE and its formative feedback. (Unpublished doctoral dissertation). Iowa State University, Ames, IA.

Cotos, E. (2014). Enhancing writing pedagogy with learner corpus data. ReCALL, 26(2), 202-224. doi:10.1017/S0958344014000019. 
Davies, M. (2008). The Corpus of Contemporary American English (COCA): 560 million words, 1990-present. Retrieved from https://corpus.byu.edu/coca/

Farr, F. (2008). Evaluating the use of corpus-based instruction in a language teacher education context: Perspectives from the users. Language Awareness, 17(1), 25-43. doi:10.2167/1a414.0.

Gaskell, D., \& Cobb, T. (2004). Can learners use concordance feedback for writing errors? System, 32(3), 301-319. doi:10.1016/j.system.2004.04.001.

Hadi, Z., \& Alibakhshi, G. (2012). On the effectiveness of corpus analysis tool in the use of correct preposition in Persian into English translation. The Iranian EFL Journal, 8(5), 284-294.

Johns, T. (1991). Should you be persuaded: Two samples of data-driven learning materials. English Language Research Journal, 4, 1-16.

Larson-Hall, J. (2015). Using an online bilingual corpus dictionary to improve word choice and grammar. Fukuoka Jo Gakuin Centre for the Study of English Language Teaching Journal (英語教育研究センター), 3, 99-109.

McGuire, M. (2018). Japanese-English Parallel Corpora in the classroom: Applications and challenges. Kansai Gaidai University Journal of Inquiry and Research (研究論集), 107, 245-259.

Mizumoto, A., \& Chujo, K. (2015). A meta-analysis of data-driven learning approach in the Japanese EFL classroom. English Corpus Studies, 22, $1-18$.

Smart, J. (2012). Innovative approaches to ESL grammar instruction. Doctoral dissertation. Northern Arizona University. ProQuest Dissertations Publishing. Retrieved from https://search.proquest.com/openview/762dd30d6f913 d01f0b01f3a8e42a04f/1?pq-origsite $=$ gscholar\&cbl=18750\&diss=y

Someya, Y. (2000). Online business letter corpus KWIC concordancer and an experiment in data-driven learning/writing. Paper presented at the $3 \mathrm{rd}$ Association for Business Communication International Conference, Doshisha University, Kyoto, Japan.

Sun, Y. -C., \& Wang, L. -Y. (2003). Concordancers in the EFL Classroom: Cognitive approaches and collocation difficulty. Computer Assisted Language Learning, 16(1), 83-94. doi:10.1076/call.16.1.83.15528.

Tian, S. (2005). The impact of learning tasks and learner proficiency on the effectiveness of data-driven learning. Pan-Pacific Association of Applied Linguistics, 9(2), 263-275.

Tian, S., \& Liu, L. (2004). Course-specific corpora in the classroom: A news media English class in Taiwan. The Journal of Asia TEFL, 1(1), 267-290.

Turnbull, J., \& Burston, J. (1998). Towards independent concordance work for students: Lessons from a case study. On-Call, 12(2), 10-21.

Utiyama, M., \& Isahara, H. (2003). Reliable measures for aligning Japanese-English news articles and sentences. Paper presented at the Proceedings of the 41st Annual Meeting on Association for Computational Linguistics Volume 1, Sapporo, Japan. 
Yang, Y. -F., Wong, W. -K., \& Yeh, H. -C. (2013). Learning to construct English (L2) sentences in a bilingual corpus-based system. System, 41(3), 677-690. doi:10.1016/j.system.2013.07.014.

\section{Websites}

Asian Scientific Paper Excerpt Corpus (ASPEC) - http://orchid.kuee.kyoto-u. ac.jp/ASPEC/

Eijiro on the WEB PRO - https://eowp.alc.co.jp/

Eijiro on the WEB - https://www.alc.co.jp/

Japanese-English News Article Alignment Data (JENAAD) - http://www2.nict. go.jp/astrec-att/member/mutiyama/jea/index.html

Japanese-English Subtitle Corpus (JESC) - https://nlp.stanford.edu/projects/jesc/

Kyoto Free Translation Task (KFTT) - http://www.phontron.com/kftt/ 


\title{
Vocabulary Learning and Instruction
}

\author{
Volume 8, Number 1,
}

March 2019

doi: http://dx.doi.org/10.7820/vli.v08.1.2187-2759 